\title{
Violência simbólica e ideologia: diálogos entre Bourdieu e Fairclough
}

\section{Symbolic violence and ideology: dialogues between Bourdieu and Fairclough}

Marta Gresechen Paiter Luzia de Souza ${ }^{1}$

\begin{abstract}
RESUMO: Esta pesquisa bibliográfica articula os conceitos de violência simbólica (BOURDIEU, 1986; 1989; 1991; 2009) e ideologia (FAIRCLOUGH, 1989; 1999a; 1999b; 2003) com a finalidade de (1) traçar aspectos de contiguidade e/ou distância entre ambas noções teóricas; (2) analisar a importância/predominância desses conceitos para a área de Estudos da(e) Lingua(gem); e (3) avaliar (res)significações das noções apresentadas no contexto de produção teórica brasileira. Para alcançar tais objetivos, realizei uma busca no Banco de Teses (CAPES), e, após determinados critérios de seleção, desenvolvi uma análise de conteúdo (BARDIN, 2011) com foco nas categorias temáticas, ou seja, nas noções conceituais de violência simbólica e ideologia. Os resultados da análise demostram que os mencionados conceitos tem contribuído para (a) repensar práticas de dominação em contextos de seleção para curso de pós-graduação; (b) refletir acerca de traços ideológicos que interpelam a constituição identitária de educadores/as; e (c) questionar a atuação social de instituições (como a mídia) na (re)produção de dominação no processo de construção identitária (sociossexual) da mulher brasileira.
\end{abstract}

PALAVRAS-CHAVE: violência simbólica. ideologia. estudos da(e) lingua(gem).

ABSTRACT: This bibliographic research articulates the concepts of symbolic violence (BOURDIEU, 1986; 1989; 1991; 2009) and ideology (FAIRCLOUGH, 1989; 1999a; 1999b; 2003) for (1) delineating aspects of contiguity and/or distance between both theoretical notions, (2) analyzing the importance/predominance of these concepts for the area of Language Studies, and (3) evaluating re-significations of notions presented in the context of Brazilian theoretical production. To achieve these objectives, I conducted a search in CAPES Bank of Thesis, and, after certain selection criteria, I developed a content analysis (BARDIN, 2011) focusing on the thematic categories, that is, the conceptual notions of

\footnotetext{
MARTA GRESECHEN PAITER LUZIA DE SOUZA é licenciada em Letras Estrangeiras Modernas Língua Inglesa e respectivas literaturas pela Universidade Estadual de Londrina (2010). Mestre pelo Programa de Pós-graduação em Estudos da Linguagem - PPGEL/UEL (2013). Atuou no Departamento de Letras Estrangeiras Modernas - LEM como professora colaboradora (2014-2016). Atualmente, é doutoranda do Programa de Pós-graduação em Estudos de Linguagem da Universidade Federal de Mato Grosso (UFMT).
} 
symbolic violence and ideology. The results of the analysis show that these concepts have contributed to (a) rethink practices of domination in selection contexts for entering graduate research programs; (b) reflect upon ideological traits that interpellate the identity constitution of educators; and (3) question the social performance of institutions (such as the media) in the re-production of domination in the process of Brazilian women identity construction.

KEYWORDS: symbolic violence. ideology. language studies.

\section{Introdução}

Este estudo consiste em uma pesquisa bibliográfica que aborda os conceitos de violência simbólica (BOURDIEU, 1986; 1989; 1991; 2009) e ideologia (FAIRCLOUGH，1989; 1999a; 1999b; 2003) de forma a (1) traçar aspectos de contiguidade/proximidade e/ou distância entre ambos, após discussão envolvendo os contextos sócio-histórico-culturais nos quais foram pensados. Ademais, tendo em vista meu interesse em estudos relacionados à minha formação acadêmica/profissional, a saber, à área de Estudos da(e) Lingua(gem) e ao campo de Formação de Educadores/as de Línguas, objetivo (2) analisar a importância/predominância desses conceitos para o referido campo e área de investigação, e/ou afins, e (3) avaliar (res)significações das noções apresentadas no contexto de produção teórica brasileira.

Para tanto, este artigo está estruturado em 3 seções. Inicialmente, apresento aspectos preliminares da Teorial Social de Bourdieu, especificamente, as noções que perpassam o conceito de violência simbólica e, igualmente, introduzo alguns pontos da Teoria Social do Discurso de Fairclough e seu conceito de ideologia. Na seção posterior, descrevo de que forma realizei o levantamento bibliográfico de estudos brasileiros que abordam essas noções conceituais para, posteriormente, apreciá-los. Por fim, apresento minha reflexão acerca do tema com foco nas possíveis contribuições/limites com base nas pesquisas e conceitos articulados. 


\section{Diálogos Conceituais Entre Bourdieu e Fairclough}

A constituição da noção conceitual violência simbólica, componente estruturante da Teoria da Violência Simbólica, proposta e desenvolvida por Pierre Bourdieu, foi motivada pela estória de vida de um camponês submetido a um processo de violência simbólica por meio do que se pode denominar 'celibato obrigatório', em uma comunidade na cidade de Béarn, no Sudoeste da França (Cf. BOURDIEU, 1962), e está situada, fundamentalmente, na discussão teórica que envolve o processo de apreciação crítica desse sociólogo francês à estruturação das relações humanas, das sociedades e dos sistemas societários como um todo.

Fundamentado em raízes marxistas, esse autor defini mundo social como "história acumulada" que pressupõe esquemas históricos e classificatórios, isto é, "produtos da divisão objetiva em classes (grupos etários, gêneros, classes sociais), cujos funcionamentos subjazem ao nível da consciência e do discurso" (1986, online) $)^{2}$. Isso significa dizer que, para Bourdieu, o processo de internalização das estruturas sociais imanentes/profundas não passa pelo discurso, como ele próprio afirma: "o que faz o poder das palavras (...), poder de manter a ordem e de a subverter, é a crença na legitimidade das palavras e daquele que as pronuncia, crença cuja produção não é da competência das palavras" (BOURDIEU, 1989, p. 15 , grifo meu).

Bourdieu institui conceitos substanciais a sua teoria (praxiológica e relacional) das estruturas sociais e mentais, tais como campo social, capital econômico, capital social, capital cultural, capital linguístico, distinção simbólica, habitus e competência linguística. Essas noções conceituais estão estruturalmente inter-relacionadas à violência simbólica, a qual implica em um processo sóciopsicológico de imposição/inculcação/dominação/legitimação (econômica, social,

2 "(...) product of the objective division into classes (age groups, genders, social classes) and which function below the level of consciousness and discourse". 
cultural, simbólica) de significações. Tal processo se instaura no interior de campos sociais, por meio de forças simbólicas dissimuladas/mascaradas, que podem ser vistas como naturais (ortodoxia).

A estrutura dos campos sociais assenta-se no que Bourdieu denomina poder simbólico, o qual "se define numa relação determinada - e por meio desta - entre os que exercem o poder e os que lhe estão sujeitos" (1989, p. 14, grifo meu); um processo que se caracteriza pelo acúmulo de capital. Acerca disso, considerando sua função de crítica social (intervenção crítica), Bourdieu e Passeron relacionam a violência simbólica às ações pedagógicas, afirmando, pois, que a/o escola/ensino formal, além de outras instâncias, se constitui um espaço/lugar, socialmente reconhecido e legitimado, para exercê-la. Para os autores, as práticas pedagógicas "reproduzem a cultura dominante, reproduzindo também as relações de poder de um determinado grupo social" (2009, p. 5, grifo meu).

Essa relação de dominação/poder (hierárquica/polar) está inserida em uma ordem social, construída por sistemas simbólicos, e conjectura uma luta simbólica, em que se distingue a cultura dominante (classe dominante), cujo poder correlaciona-se ao capital econômico, de denominadas/designadas subculturas (classe dominada). É, principalmente, a partir desse aspecto teórico que pesquisas educacionais, fundamentadas nas análises sociológicas de Bourdieu, questionam, por exemplo, a definição de reais condições de igualdade de aprendizagem(ns) oferecidas a educandos/as, considerando que a ação pedagógica costuma "produzir o desconhecimento da verdade objetiva do arbítrio cultural imposto" (BOURDIEU; PASSERON, 2009, p.8) e que "as ideologias servem interesses particulares que tendem a apresentar como interesses universais, comuns ao conjunto do grupo" (BOURDIEU, 1989, p.10, grifo meu).

Em seu estudo, Kramsch (2008), professora de francês e alemão no Instituto de Tecnologia de Massachusetts à época, relata suas experiências pessoais/profissionais como educanda e educadora (autoridade pedagógica). Após 
um processo de autoidentificação com a história de vida de Bourdieu, pela leitura de sua obra sociofilosófica "Ce que parler veut dire" (1982), se percebeu, reproduzindo práticas de violência simbólica, e, consequentemente, contribuindo para a reprodução da ordem social, conforme conclui: "Percebi que, em virtude da minha formação em nível superior, era esperado que eu usasse meus conhecimentos dos escritores ${ }^{3}$, não para colocar a instituição educacional em questão, mas para reproduzir a dominação de classe para a qual fui treinada" (2008, p. 35, grifo meu) ${ }^{4}$.

Para Bourdieu, os processos de produção ideológica não são "passíveis de uma análise pura e puramente interna", ao mesmo tempo, deve-se "evitar o etnologismo que consiste em tratar as ideologias como mitos, quer dizer, como produtos indiferenciados de um trabalho coletivo" (1989, p. 13, grifo meu). Por essa razão, tendo como base o conceito de violência simbólica, Bourdieu buscou revelar os diversos modos de reprodução e dominação, socialmente legitimadas, conhecer os processos dos quais decorrem e, "analisar a competência dos atores sociais para enfrentá-los (MORATO; BENTES, 2002, p.32).

Sabendo que "os esquemas de percepção e apreciação (..), sedimentados na linguagem, são produtos das lutas simbólicas anteriores e exprimem, de forma mais ou menos transformada, o estado das relações de força simbólica" (BOURDIEU, 1989, p. 139-140, grifo meu), faz-se possível conhecer o mundo, as formas de dominação, por meio de uma análise da/o língua(gem)/discurso e suas dimensões simbólicas, uma vez que o processo analítico englobe "as condições sócio-históricas dentro das quais o objeto de análise é produzido" ${ }^{\prime \prime}$, como aponta Thompson na seção introdutória de "Linguagem e Poder simbólico" (BOURDIEU,1991, p. 29).

3 "[Pascal, Ricoeur, Bachelard, Merleau-Ponty, the existentialists Sartre, Camus, and Gabriel Marcel, the German philosophers, Nietzsche, Heidegger, and Jaspers]".

4 "I realized that by virtue of my higher education I was expected to use my knowledge of these writers, not to put the educational institution into question, but to reproduce the dominance of the class I had been trained to belong to.

5 "(...) socio-historical conditions within which the object of analysis is produced". 
Tendo abordado alguns dos fundamentos da Teoria da Violência Simbólica de Bourdieu, neste momento, introduzo algumas noções que considero importantes para a compreensão do conceito de ideologia, com base na Teoria Social do Discurso, na/o perspectiva/modelo teórico-metodológica/o da Análise Crítica do Discurso $(A C D)$ de vertente britânica, elaborada pelo autor inglês Norman Fairclough no final do século XX. Relacionalmente, focalizo aspectos de contiguidade/proximidade e distância, principalmente, entre os conceitos de ideologia e violência simbólica.

A tradição materialista, assim como na teoria de Bourdieu, perpassa a ACD de Fairclough. Suas bases filosóficas tem influência do Marxismo Ocidental "que enfatiza aspectos culturais da vida social ao entender que as relações de dominação e exploração são determinadas e perpetuadas cultural e ideologicamente" (TÍLIO, 2010, p. 89). Ademais, a crítica e o questionamento de problemas sociais são concebidos como elementos fundamentais para a compreensão/análise de fenômenos que estruturam a sociedade (relações de poder/dominação).

Em sua obra "Language and Power", publicada em 1989, Fairclough estabelece uma interface entre Linguística e Sociologia e define linguagem como discurso (prática social/ entidade intermediária) ${ }^{6}$. Com isso, busca explicar a interrelação (dialética) entre linguagem e sociedade. Nessa concepção, é possível notar uma distância entre Bourdieu e Fairclough, como explico no início dessa seção, pois para esse último a linguagem pode tanto instaurar relações de poder/dominação quanto, contrariamente, possibilitar a superação de problemas sociais, como ele próprio sintetiza: "Discurso tem efeitos sobre estruturas sociais:

\footnotetext{
6 "I shall look at texts as elements of concrete social events, which are both shaped by and shape more abstract and durable social structures and social practices" (FAIRCLOUGH, 2003, p. 16).
} 
ao mesmo tempo em que é determinado por elas, contribui para a permanência/mudança social" (FAIRCLOUGH, 1989, p. 16)7.

Em sua obra "Language and Symbolic Power", publicada em 1991, Bourdieu explora uma compreensão/abordagem sociológica da linguagem, adentrando o campo da linguística e da análise discursiva, e questiona, juntamente com Passeron, práticas da sociolinguística que, para esses teóricos, se distanciavam da concepção de língua como fenômeno sócio-histórico. Diante disso, Bourdieu argumenta que é necessário "transcender os limites em que se inscrevem as reais intenções da linguística estrutural como uma teoria pura" (1991, p. 33) ${ }^{8}$. Suas asserções provocam debates acadêmicos, bem como, críticas direcionadas, por representantes da análise crítica do discurso, à Bourdieu.

Em 1999, Chouliaraki e Fairclough posicionam-se às críticas de Bourdieu aos estudos linguísticos e discursivos. Em primeiro lugar, demonstram ponderação acerca da possibilidade de se tornarem demasiamente estruturalistas/objetivistas (MYLES, 2010). Em segundo lugar, compartilham com Hasan, expoente da Linguística Sistêmica Funcional (LSF), o questionamento ao conceito de discurso para Bourdieu, que não considera o princípio constitutivo da linguagem pela $A C D$, ou seja, de constituir-se e ser constituída nas/por meio das relações sociais (relação dialética entre prática social, discurso/linguagem, e sociedade), atribuindo à/ao linguagem/discurso um papel secundário (CHOULIARAKI; FAIRCLOUGH, 1999a), segundo afirmam. Assim, tendo com base o conceito da ACD para linguagem, os autores concluem seu posicionamento colocando em questão o conceito de Bourdieu em que capital linguístico é tido como integrante das lutas classificatórias.

O conceito de ideologia para Fairclough está centrado no entendimento de poder como hegemonia (GRAMSCI, 1988), sendo essa última "uma forma

\footnotetext{
7 "Discourse has effects upon social structures, as well as being determined by them, and so contributes to social continuity and social change".

8 "(...) one transcends the limits which are inscribed in the very intention of structural linguistics as pure theory".
} 
particular (...) de conceitualizar o poder e a luta pelo poder, em sociedades capitalistas, que salienta como o poder depende do consentimento ou da aquiescência ao invés de apenas força" (FAIRCLOUGH, 2003, p. 218, grifo meu)9. Para a ACD, os sentidos e/ou efeitos ideológicos (representações) estão intrinsecamente relacionados ao texto/discurso. Por isso, seu papel é, precisamente, investigar/desvelar os níveis mais abstratos e estruturais dos efeitos do textos, sejam eles os de inculcar e/ou os de mudar ideologias. Fairclough conclui, "se as ideologias são primariamente representações, elas podem também ser 'legitimadas' pelos modos de agir socialmente e, 'inculcadas' nas identidades dos agentes sociais" ( 2003, p.9, grifo meu).

Para Bourdieu, as lutas para manter ou "alterar as formas de capital" acontecem dentro de um campo, em que agentes sociais, ao ocupar diferentes posicões sociais, "pelas distribuições de diferentes tipos de capitais" (1989, p. 231), apresentam diferentes objetivos. Nessa estrutura, as ideologias se constituem instrumentos (simbólicos) de dominação, assim como o próprio poder (simbólico), o qual é acumulado por agentes sociais/instituições, definido como "aquele poder invisivel que somente pode ser exercido com a cumplicidade daqueles que não querem ter conhecimento de que eles estão submetidos a ele ou mesmo se eles próprios o exercitam" (1991, p. 164-165, grifo meu) ${ }^{10}$. Nesse processo, a violência simbólica "é o mecanismo pelo qual o poder é exercido" (THOMPSON, 1991, p. 23).

Uma leitura analítica de ambas teorias permite compreender um aspecto que, fundamentalmente, evidencia a distinção entre as noções conceituais criadas por Bourdieu e Fairclough em destaque neste estudo: Bourdieu ressalta o caráter 'durável' do "efeito da inculcação e da imposição, juntamente com as sanções,

\footnotetext{
9 "A particular way (associated with Gramsci) of conceptualizing power and the struggle for power in capitalist societies, which emphasizes how power depends on consent or acquiescence rather than just force".

10 "For symbolic power is that invisible power which can be exercised only with the complicity of those who do not want to know that they are subject to it or even that they themselves exercise it."
}

Entretextos, Londrina, v. 17, n. 1, p. 361 - 377, jan./jun. 
implementadas pelo sistema educacional" (1991, p. 90, grifo meu); afirma que a condição para a manutenção do privilégio reside nas 'disposições duráveis'; (1991, p. 122, grifo meu); e que "as relações de poder são institucionalizadas em status sociais duráveis, que são socialmente reconhecidos ou legalmente garantidos, entre agentes que são objetivamente definidos por suas posições no interior dessas relações" (1991, p. 231, grifo meu). Por outro lado, Fairclough, fundamentado na definição de instabilidade do poder pela $A C D$, caracterizado como temporário, defende e enfatiza o argumento de que modos de agir socialmente (a materialização de discursos/práticas sociais) são capazes de legitimar ideologias e "contribuir para sustentar e mudar as relações de poder" (2003, p.9, grifo meu).

\section{Estudos Brasileiros Sobre Violência Simbólica E Ideologia}

Julgo relevante mencionar os procedimentos metodológicos, realizados para alcançar os objetivos previamente descritos, não para demonstrar 'filiação metodológica' e/ou "exibição ostentatória" (BOURDIEU, 1989, p.26), porém com vistas à apresentação e organização do relato de como represento esse processo, não se trantando, portanto, de uma ação neutra. Por conseguinte, estou ciente de que ele é substancialmente complexo e dialético e, deste modo, não se reduz a uma técnica de análise. Assim, os movimentos deste estudo consistiram em um processo analítico-interpretativo-semântico dos textos, encontrados por meio de um levantamento bibliográfico, e incluem: pré-análise, exploração do material, inferência e interpretação - análise de conteúdo (BARDIN, 2011, p. 121).

Primeiramente, ao longo da pré-análise, em 17 de outubro de 2016, realizei uma busca no Banco de Teses, componente do Portal de Periódicos da Capes/MEC, que disponibiliza as dissertações e teses defendidas a partir de 1987, por meio dos termos violência simbólica e ideologia e, em seguida, selecionei 
aquelas pertencentes às áreas de concentração que apresentam em sua nomenclatura as denominações 'linguagem'(ns), 'língua'(s), 'inglês/língua inglesa' e/ou 'formação de educadores(as)/professores(as)'.

Para o termo violência simbólica, foram elencados, inicialmente, um total de 290 registros, pertencentes a 88 diferentes áreas de concentração. Após o recorte para este estudo, restaram 6 pesquisas. Com relação a ideologia, à princípio, foram listados 5976 títulos, pertencentes a 479 diferentes áreas de concentração, sendo que após o mesmo procedimento, remasceram 128 produções.

Como o enfoque deste trabalho está, especificamente, nas pesquisas fundamentadas em uma das noções teóricas mencionadas, a ação subsequente foi buscar, no título, no resumo e nas palavras-chave de cada uma das 134 pesquisas, referências aos autores Bourdieu e/ou Fairclough. Dessa forma, das 6 pesquisas, permaneceram 4, defendidas nos anos de 2013 e 2015, e das 128, permaneceram 23, sendo 2014 e 2015 os anos correspondentes à defesa, restando assim um total de 29 estudos.

O último critério de seleção foi escolher uma pesquisa de cada ano que tivesse maior proximidade com minha área de interesse anteriormente explicitada. Essa ação se deve, principalmente, pelo limite do espaço de discussão deste artigo. Os dados de análise, portanto, são 3 dissertações (ARAÚJO, 2013; LOPES, 2015; OLIVEIRA, 2015) e 1 tese (BATISTA, 2014), concernentes às respectivas áreas de concentração/ linhas de pesquisa: Linguagem e Interação/Estudos críticos da linguagem; Linguagem e Sociedade/Discurso, representações sociais e textos; Linguagens e Letramentos/Leitura e produção textual: diversidade social e práticas docentes; Linguagem e Sociedade/Discurso, representações sociais, e textos.

Em seguida, durante o processo de exploração do material, voltei-me à análise das categorias temáticas, ou seja, das noções conceituais de violência simbólica e ideologia. Esse momento está, dialeticamente, atrelado ao procedimento de inferência e interpretação, o qual fundamenta-se nos 
pressupostos teóricos de Bourdieu e Fairclough, circunscritos ao foco desta análise, e compreende explicitar os objetos de estudo das nomeadas investigações relacionados a seus contextos de pesquisa/intervenção, conforme disserto a seguir.

O estudo desenvolvido por Araújo (2013) apresenta como conceito-chave e elemento norteador das discussões a violência simbólica, presente no título, no resumo, nas palavras-chave e reiterada ao longo da pesquisa. Seu objeto de investigação está centrado na relação simbólica que o autor estabelece entre a violência simbólica e contextos de seleção de pós-graduação em instituições públicas de Fortaleza-CE (sub-campos), materializados em editais para cursos de mestrado.

Segundo o referido autor, os sentidos que caracterizam esse campo acadêmico estão voltados para coerção, tensão, submissão, silenciamento, censura e adesão entre a academia (avaliadores) e os acadêmicos (candidatos à academia), cuja relação (de poder/dominação concreta) é definida sobretudo pelo capital científico/cultural. Fundamentado em Bourdieu, Araújo argumenta que essa relação simbólica constitui violência simbólica devido à "exacerbação de sua assimetria" na "adesão que o candidato não pode deixar de conceder à autoridade acadêmica" (2013, p. 14, grifo meu).

As significações tecidas acerca do conceito de violência simbólica perpassam os sentidos de poder regulador, não reconhecido como tal, de imposição de um regime de verdade, por autoridade legítimas, constituído por elementos duráveis e invisíveis, que encerram uma aceitação tácita como um processo natural. Dentre as categorias analíticas e sentidos probematizados que configuram a violência simbólica, pela materialidade linguística apresentada por Araújo (2013), destaco: discurso/linguagem eufemizado/a, polidez, processo à priori sem a garantia de um ganho, enunciados explícitos de normas/regras (conformação pela inculcação). Para o pesquisador, a contribuição dessa análise está em reivindicar práticas de 
poder menos assimétricas no que se refere às situações empíricas descritas, por meio de (res)significações e 'modificações nos dispositivos dos editais' (política de inclusão/exclusão).

O trabalho de Oliveira (2015), da mesma forma, baseia-se na noção de violência simbólica, contudo, diferentemente da pesquisa de Araújo (2013), seu eixo central de investigação é a presença/ausência e representação de mulheres negras em livros didáticos de Língua Portuguesa. Especificamente no resumo da pesquisa, ao delinear seus conceitos base, a autora reconhece não ter conhecimento aprofundado dos estudos Bourdieusianos, e, ao longo do texto, reitera: "enfatizamos que não somos especialistas em Bourdieu e Passeron" (2015, p. 22) e "enfatizamos que esses autores servirão apenas para o início da reflexão" (2015, p. 18). Neste sentido, há poucas instanciações de (res)significação do conceito de violência simbólica e, em suas asserções, é possível notar que não há uma preocupação em definir certos elementos constituintes do processo da violência simbólica. Para a pesquisadora, esse conceito "pode ser entendido como um tipo de mecanismo que cria, legitima e reproduz a desigualdade social" (2015, p. 21).

Sobre essa investigação, entendo ser problemática, em relação à qualidade da pesquisa, a não articulação do conceito de violência simbólica no decorrer da dissertação, incluindo a não retomada desse tema nas reflexões finais, tendo sido abordado na seção 'Considerações Teóricas' e considerado importante para compreender a presença/ausência de determinados temas nos currículos/livros didáticos. Esses aspectos denotam uma certa fragmentação teórica/conceitual, especialmente, pelo não estabelecimento de diálogo entre os conceitos dos pressupostos teórico-metodológicos, indicado como finalidade pela própria autora no início do texto: "nossa intencionalidade é realizar um diálogo com os autores que seguem: Bourdieu e Passeron (1998) e Althusser (1970)" (OLIVEIRA, 2015, p.20, grifo meu). 
Batista (2014) tem como foco de pesquisa as ideologias subjacentes aos processos de representação e constituição identitária de docentes em charges. Para isso, fundamenta-se na Análise de Discurso Crítica (ADC) de Fairclough, que, por sua vez, está sustentada na teoria social crítica, bem como nas/nos estratégias/operadores de ideologia de John B. Thompson, que contribuem na formação das categorias analíticas do estudo. Assim como a ACD, a autora caracteriza a/os ideologia/traços ideológicos como inerentemente negativa/os devido a sua natureza hegemônica e, portanto, critica/questiona uma suposta neutralidade veiculada por discursos midiáticos. Seu propósito de pesquisa está diretamente relacionado à preocupação da $A C D$ de investigar/desvelar os efeitos ideológicos (as relações de poder e dominação) (dos sentidos) de textos, muitas vezes, naturalizados, acerca da identidade docente. Ao definir discurso como prática social ou parte dela (FAIRCLOUGH, 1989), realça sua característica potencial de sustentar/legitimar ideologias. No diálogo entre Fairclough e Thompson, há uma (res)significação dos sentidos para ideologia em referência a "atitudes, conjunto de crenças, valores e doutrinas" (2014, p.97). Os sentidos extremamente negativos nas charges sobre docentes leva a autora a confirmar a relação dialética entre traços ideológicos e constituição identitária. Por isso, conclui que a análise crítica pode ser um instrumento que possibilite mudanças na identidade de docentes.

Assim como Batista (2014), Lopes (2015) investiga identidades, especificamente, a identidade sociossexual feminina da mulher brasileira, por meio de uma análise discursiva das relações interdiscursivas e intertextuais do discurso midiático, em 3 revistas selecionadas. Seu arcabouço teórico-metodológico também coincide com o de Bastista (2014), certamente, porque ambos estudos foram desenvolvidos sob orientação da mesma orientadora. Para tanto, os sentidos atribuídos à ideologia são similares. Segundo Lopes (2015, p. 54), as revistas analisadas "impõem ideologias favoráveis à manutenção da economia neoliberal". 
Alguns dos sentidos que perpassam o processo analítico-discursivo deste trabalho, com foco na identidade sociossexual feminina, apontam para a construção de estereótipos, tais como: 'Somente homem fala de sexo'; 'Somente homem recebia educação sexual'; 'Mulher não tem direito ao sexo antes do casamento'; 'Não ser virgem é pecado'; 'Homosexualidade considerada doença, loucura'; 'Mulher sem valor moral'; 'Mulher tem que sentir dor por causa do pecado original'; 'Controle do corpo pela religião'; 'Sexo não é bom, saudável para mulheres "sérias"'.

\section{Reflexões Finais}

Enfatizo que não é objetivo deste trabalho fazer comparações com outros quadros teóricos, estabelecer prescrições ou tecer generalizações, já que isso vai de encontro às minhas concepções ontológicas e epistemológicas, por entender serem as realidades das dinâmicas educacionais e linguísticas brasileiras caracterizadas por suas complexidades e idiossincracias contextuais/culturais. Por este motivo, nesse momento, retomo as noções abordadas e saliento as possíveis contribuições/limites com base nas pesquisas e conceitos articulados.

As reflexões teóricas deste estudo, no que se refere ao diálogo entre Bourdieu e Fairclough, apontam para uma relação que, a despeito das diferenças teórico-filosóficas, pode ser caracterizada como uma relação de mútuas contribuições, visto que Bourdieu e Wacquant (2001) sinalizam a importância das contribuições de analistas do discurso para a pesquisa social e, Fairclough (2003), articula os conceitos de 'campo social', 'habitus', 'classificação' de Bourdieu a sua teoria. E, além disso, Fairclough reconhece "serem, frequentemente, os teóricos sociais aqueles que produzem os conhecimentos críticos mais interessantes sobre a linguagem como elemento da vida social" (2003, p. 204) ${ }^{11}$.

\footnotetext{
11 "It is often social theorists who produce the most interesting insights about language as an element of social life".
} 
Sobre as pesquisas analisadas, um aspecto inicial relevante que se pode observar é o período significativamente recente dessas produções acadêmicas, desenvolvidas nos últimos 3 anos. Dessa forma, os conceitos de violência simbólica e ideologia, cunhados nas décadas de 60 e 90, respectivamente, tem sido (res)significados em contextos brasileiros atuais, na área de linguagens/sociedade, e contribuído para:

a) Repensar práticas de dominação em contextos de seleção para curso de pós-graduação;

b) Refletir acerca de traços ideológicos que interpelam a constituição identitária de educadores/as;

c) Questionar a atuação social de instituições (como a mídia) na (re)produção de dominação no processo de construção identitária (sociossexual) da mulher brasileira.

Por intermédio dessa investigação, concluo que, com base nas pesquisas e conceitos abordados, os limites das noções conceituais discutidas podem ser (res)significados à medida que se estabeleça uma coerência teórico-filosóficametodológica articulada às condições sócio-histórico-culturais do processo de (re)criação das realidades.

Como pesquisadora, estou consciente de que os procedimentos metodológicos para seleção dos dados de análise deste estudo limitam seus resultados e conclusões. Por isso, futuras contribuições de pesquisas longitudinais neste âmbito são substancialmente necessárias para expandir as significações tecidas nos estudos brasileiros acerca das noções teóricas discutidas neste trabalho.

\section{Referências}


ARAÚJO, Carlos Sidney Avelar. Violência simbólica nos editais de seleção de programas de pós-graduação: uma abordagem linguístico-sociológica. 2013. 126 f. Dissertação. (Mestrado em Linguística Aplicada) - Universidade Estadual do Ceará, Fortaleza, 2013.

BATISTA, Eni Abadia. Identidades de docentes brasileiros e suas representações discursivas em charges. 2014. 208 f. Tese. (Doutorado em Linguística) Universidade de Brasília, Brasília, 2014.

BARDIN, Laurence. Análise de conteúdo. São Paulo: Edições 70, 2011.

BOURDIEU, Pierre. Célibat et condition paysanne. Études rurales, v. 5, n. 6, p. 32136, 1962.

BOURDIEU, Pierre. The Forms of capital. 1986. Disponível em: < https://www.marxists.org/reference/subject/philosophy/works/fr/bourdieu-formscapital.htm>. Acesso em: 29 set. 2016.

BOURDIEU, Pierre. O poder simbólico. Rio de Janeiro, RJ: Editora Bertrand Brasil, 1989

BOURDIEU, Pierre. Language and symbolic power. Ed. by John B. Thompson. Trans. by Gino Raymond and Matthew Adamson. Cambridge, MA: Harvard University Press, 1991.

BOURDIEU, Pierre; WACQUANT, Loic. New-Liberal Speak: notes on the new planetary vulgate. Radical Philosophy, p.2-5, 2001.

BOURDIEU, Pierre; PASSERON, Jean-Claude. A Reprodução: Elementos para uma Teoria do Sistema de Ensino. In: Rosendo, A. P. Coleção: Recensões LUSOSOFIA, Portugal, Covilhã, 2009.

CHOULIARAKI, Lilie; FAIRCLOUGH, Norman. Language and Power in Bourdieu: a Response to Hasan's "The Disempowerment Game". Linguistics and Education, p. 399-409, 1999a. 
CHOULIARAKI, Lilie; FAIRCLOUGH, Norman. Discourse in late modernity: rethinking Critical Discourse Analysis. Edinbourg: Edinbourg University Press, 1999b.

FAIRCLOUGH, Norman. Language and Power. Londres: Longman, 1989.

FAIRCLOUGH, Norman. Analysing discourse: textual analysis for social research. London: Routledge, 2003.

GRAMSCI, Antonio. A Gramsci Reader: Selected Writings 1916-1935. David Forgacs (Org.). London: Lawrence and Wishart, 1988.

KRAMSCH, Claire. Pierre Bourdieu: a Biographical Memoir. In: Albright, J.; A. Luke. (Ed.). Pierre Bourdieu and literacy education. New York: Routledge, 2008. LOPES, Elizabete Nepomuceno Raiol. $A$ identidade sociossexual da mulher brasileira: seis décadas de discursos na mídia revista. 2015. 162 f. Dissertação. (Mestrado em Linguística). Universidade de Brasília. Brasília, 2015. MORATO, Edwiges; BENTES, Anna Christina. Das intervenções de Bourdieu no campo da lingüística: reflexões sobre competência e língua legítima. Horizontes, v.20, p. 31-48, 2002.

MYLES, John. Bourdieu, Language and the Media. New York: Palgrave Macmillan, 2010.

OLIVEIRA, Georgette Vanessa Janaina Chaves de. Mulheres negras no livro didático de língua portuguesa: uma história a ser contata. 2015. 128 f. Dissertação. (Mestrado Profissional em Letras) - Universidade Estadual de Londrina, Londrina, 2015.

TÍLIO, Rogério. Revisitando a análise crítica do discurso: um instrumental teóricometodológico. Rev Curso de letras da UNIABEU. p.86-102, 2010. 